\title{
Resistência anti-helmíntica em rebanhos comercias de ovinos nos municípios de Castro e Fazenda Rio Grande, PR
}

José Leonardo Sviech Ratim;, Maria Christine Rizzon Cintra, Douglas Otenio, Rüdiger Daniel Ollhoff, Cristina Sotomaior

Programa de Pós-Graduação em Ciência Animal, Pontifícia Universidade Católica do Paraná (PUCPR), Curitba, PR, Brasil

*Autor correspondente

e-mail: leonardoratim@hotmail.com

\section{Resumo}

A resistência anti-helmíntica causa grandes prejuízos na produção de pequenos ruminantes, resultante da exposição dos parasitos aos anti-helmínticos $(\mathrm{AH})$ de forma massal, sistemática e indiscriminada. 0 Brasil tem registros de resistência a todas as classes de $\mathrm{AH}$, inclusive ao monepantel, o mais recentemente lançado. 0 objetivo do presente trabalho foi avaliar a eficácia dos diferentes AH utilizados em rebanhos comerciais de ovinos na região de Castro e no município de Fazenda Rio Grande. 0 estudo foi realizado entre agosto e setembro de 2016. Em cada propriedade foi testado o monepantel e os princípios ativos que rotineiramente eram utilizados. Realizou-se o Teste de Redução na Contagem de Ovos nas Fezes (TRCOF), com contagem de ovos por grama de fezes (opg) sensível para 50 opg. Para cada princípio ativo testado, e para o grupo controle, foram utilizados no mínimo 10 animais. No TRCOF, no dia zero (D0), os ovinos foram tratados com AH e foram colhidas amostras individuais de fezes. Somente grupos com pelo menos 10 animais com mais de 500 opg foram avaliados no dia 14 (D14). Foi realizada a coprocultura para identificação do gênero dos parasitos. Considerou-se resistente o princípio ativo cuja redução no opg fosse menor que $90 \%$. No D0, foram avaliadas 11 propriedades, com 498 ovinos. Levando em conta os critérios de exclusão, no D14 foram avaliadas cinco propriedades (A, B, C, D e E). 0 levamisol foi ineficaz em todas as propriedades onde foi testado (B C, D), com redução de opg variando de 59\% a 66\%. Para a moxidectina, a redução foi de $66 \%$ (C). Houve aumento de $39 \%$ para o nitroxinil (C) e de 35\% para a doramectina (D). 0 monepantel apresentou redução acima de $95 \%$ em todas as propriedades, exceto na propriedade A, na qual a redução foi de $89 \%$, único rebanho com uso prévio do princípio ativo. Nas coproculturas, observou-se resistência do Haemonchus spp. ao monepantel na propriedade A e, na propriedade C, ao levamisol. 0 Trichostrongylus spp. foi resistente ao levamisol na propriedade $\mathrm{C}$, ao monepantel nas propriedades $\mathrm{A}$ e $\mathrm{E}$, e à associação do monepantel com o levamisol na propriedade E. Para o Oesophagostomum spp., verificou-se resistência 
apenas ao monepantel na propriedade A. Conclui-se que todos os anti-helmínticos de uso rotineiro apresentaram resistência nas propriedades estudadas. 0 monepantel, embora eficaz na maioria delas, apresentou ineficácia na propriedade onde já era utilizado, reforçando a necessidade de mudanças na forma de uso dos $\mathrm{AH}$, utilizando o tratamento seletivo. 